\title{
Access to medicines and diagnostic tests integral in the management of diabetes mellitus and cardiovascular diseases in Uganda: insights from the ACCODAD study
}

Davis Kibirige ${ }^{1 *}$, David Atuhe ${ }^{2}$, Leaticia Kampiire ${ }^{3}$, Daniel Ssekikubo Kiggundu ${ }^{4}$, Pamela Donggo ${ }^{5}$, Juliet Nabbaale ${ }^{6}$, Raymond Mbayo Mwebaze ${ }^{7}$, Robert Kalyesubula ${ }^{8}$ and William Lumu9 ${ }^{9}$

\begin{abstract}
Background: Despite the burgeoning burden of diabetes mellitus (DM) and cardiovascular diseases (CVD) in low and middle income countries (LMIC), access to affordable essential medicines and diagnostic tests for DM and CVD still remain a challenge in clinical practice. The Access to Cardiovascular diseases, Chronic Obstructive pulmonary disease, Diabetes mellitus and Asthma Drugs and diagnostics (ACCODAD) study aimed at providing contemporary information about the availability, cost and affordability of medicines and diagnostic tests integral in the management of DM and CVD in Uganda.

Methods: The study assessed the availability, cost and affordability of 37 medicines and 19 diagnostic tests in 22 public hospitals, 23 private hospitals and 100 private pharmacies in Uganda. Availability expressed as a percentage, median cost of the available lowest priced generic medicine and the diagnostic tests and affordability in terms of the number of days' wages it would cost the least paid public servant to pay for one month of treatment and the diagnostic tests were calculated.

Results: The availability of the medicines and diagnostic tests in all the study sites ranged from $20.1 \%$ for unfractionated heparin (UFH) to $100 \%$ for oral hypoglycaemic agents (OHA) and from $6.8 \%$ for microalbuminuria to $100 \%$ for urinalysis respectively. The only affordable tests were blood glucose, urinalysis and serum ketone, urea, creatinine and uric acid. Parenteral benzathine penicillin, oral furosemide, glibenclamide, bendrofluazide, atenolol, cardiac aspirin, digoxin, metformin, captopril and nifedipine were the only affordable drugs.

Conclusion: This study demonstrates that the majority of medicines and diagnostic tests essential in the management of DM and CVD are generally unavailable and unaffordable in Uganda. National strategies promoting improved access to affordable medicines and diagnostic tests and primary prevention measures of DM and CVD should be prioritised in Uganda.
\end{abstract}

Keywords: Availability, Cost, Affordability, Diabetes mellitus, Cardiovascular diseases, Low and middle income countries

\footnotetext{
* Correspondence: kibirigedavis@gmail.com

${ }^{1}$ Department of Medicine, Uganda Martyrs Hospital Lubaga, P.O.BOX 7146

Kampala, Uganda

Full list of author information is available at the end of the article
} 


\section{Background}

Globally, the prevalence of diabetes mellitus (DM) and cardiovascular diseases (CVD) has significantly reached epidemic levels especially in the low and middle income countries (LMIC) [1, 2]. This poses a colossal public health threat. Both DM and CVD adversely affect productivity, reduce quality of life, increase rates of mortality and cause a massive economic strain to a nation's health systems, families and individuals [3].

Challenges like suboptimal screening, diagnosis and management of DM and CVD coupled with low access to affordable essential medicines and diagnostic tests remain frequent in clinical practice in LMIC [4-11]. Improved access to affordable essential medicines and diagnostic tests is an integral component of optimal management of DM and CVD [12]. This directly reduces morbidity and mortality due to DM and CVD.

Due to significant socio-economic and lifestyle changes coupled with the drastic population growth, Uganda is currently experiencing an epidemiological transition from communicable diseases (CD) like tuberculosis and HIV to non communicable diseases (NCD) like DM and hypertension (HT) [13]. Two recently concluded nationwide representative studies to determine the burden of DM [14] and HT [15] in Uganda using the WHO STEP-wise methodology documented the prevalence of DM and HT of 1.4 and $26.4 \%$ respectively, with the majority of the participants unaware of their condition. Heart diseases notably hypertensive heart disease, rheumatic heart disease and dilated cardiomyopathy and related complications like acute heart failure and atrial fibrillation are frequently encountered in clinical practice in Uganda [16-18].

Despite the increasing burden of DM and CVD in Uganda, the structuring of the health system impedes provision of optimal DM and CVD care. The majority of lower tier public hospitals (health centres 1, 2, 3 and 4) which are easily accessible to the general population are more oriented towards management of CD as opposed to NCD. Patients with NCD are often referred to higher tier public hospitals (district referral or national referral hospitals) and the costly private hospitals for further management. Preliminary findings from 1 multicentre study reported that the majority of these lower tier Ugandan public hospitals lacked the recommended national and international guidelines of management of NCDs and essential medicines and diagnostic tests [19].

There is limited contemporary data about the availability, cost and affordability of medicines and diagnostic tests integral in the management of DM and CVD in Uganda. Annually, the Medicines Transparency Alliance conducts an assessment of availability and affordability of 40 essential medicines for CD and NCD in the 4 regions of Uganda using the World Health Organization
(WHO) and Health Action International (HAI) standardised method. The most recent survey done in May to June 2015 assessed only 5 NCD drugs (Glibenclamide $5 \mathrm{mg}$, Metformin $500 \mathrm{mg}$, Nifedipine retard $20 \mathrm{mg}$, Furosemide $40 \mathrm{mg}$ and Propranolol $40 \mathrm{mg}$ ) in 112 public, private and private not-for-profit health facilities. The availability of glibenclamide ranged from $36 \%$ in rural private hospitals to $80 \%$ in urban private health facilitates while the availability of metformin ranged from $36 \%$ in rural private for profit health facilities to $90 \%$ in urban public health facilities. Low availability of nifedipine and Propranolol was noted in all the public hospitals $(\leq 55 \%)$ [20].

Using the WHO and HAI standardised method for surveying medicine prices in LMIC [21], the ACCODAD study sought to add to the existing information about extent of availability, cost and affordability of medicines and diagnostic tests of NCD in Uganda and in LMIC. This information will be pivotal in influencing the formulation and implementation of national policies aimed at improving access to affordable medicines and diagnostic tests for DM and CVD.

\section{Methods}

Study settings and selection of study sites

The ACCODAD study was conducted from 15th January 2017 to 28th February 2017 in 22 public hospitals, 23 private hospitals and 100 privately owned pharmacies. The health units were selected from each of the 4 regions of Uganda (central, western, eastern and northern) using random sampling method from the hospital and private pharmacy registries of the Ministry of Health and National Drug Authority (NDA), Republic of Uganda respectively.

The total number of public and private hospitals in Uganda is 155. Two of these are national referral hospitals, 14 are regional referral hospitals and 139 are general hospitals. In terms of ownership, 65 are government owned, 63 private not for profit (PNFP) and 27 are private for profit [22]. The public hospitals offer free medical care to all patients. They procure all their drugs, laboratory tests and medical equipment from one central national procurement institution called the National Medical Stores (NMS). The NMS purchases the essential drugs and diagnostic tests from qualified private suppliers through a locally publicised tender process. Nevertheless, recurrent drug stock outs and unavailability of key diagnostic tests remains a key challenge in the public hospitals. This compels patients to seek medical treatment from the costly privately owned hospitals, clinics and pharmacies. These procure their medicines and diagnostic tests from several private distributors. The NDA registry has a total of 599 registered privately owned retail pharmacies and 90 private hospital pharmacies dealing in human medicines. The majority of the private pharmacies (>70\%) are located in the central region [23]. 
The public hospitals, private hospitals and private pharmacies where the data was collected accounted for 34, 26 and $15 \%$ of total national registered public hospitals, private hospitals and private pharmacies respectively. The majority of the study sites were selected from the central region of the country $(N=83,57.2 \%)$ because it has the greatest number of registered hospitals and privately owned pharmacies. Study sites selected from the eastern, western and northern region accounted for 15.9, 17.9 and $9 \%$ respectively.

\section{Sample size estimation}

Basing on one of the primary objectives of the ACCODAD study i.e. to determine the availability of the medicines and diagnostic tests of interest, the availability of 4 key medicines in DM and CVD management (intermediate insulin or insulitard ${ }^{\oplus}$, losartan, simvastatin and isosorbide mononitrate) of $10 \%$ as reported by the study performed in Western Cameroon was used as the prevalence (P) [6]. Using the formula: $\mathrm{n}=\mathrm{Z} 2 \mathrm{P}(1-\mathrm{P}) / \mathrm{d} 2$ where $\mathrm{Z}$ (normal value corresponding to the $95 \%$ confidence interval) $=1.96$, $P=0.1$ and $\mathrm{d}=0.05$ (desired precision of estimation), a sample size of 138 health units (hospitals and private pharmacies) was obtained. The study sample size was however, increased to 145 .

\section{Data collection}

For the ACCODAD study, we collected information about 37 medicines and 19 diagnostic tests significant in the management of DM and CVD as highlighted by the Ugandan local guideline and several international guidelines as highlighted below. The CVD of interest were hypertension, coronary artery disease, stroke, dilated cardiomyopathy, rheumatic heart disease, atrial fibrillation, peripheral arterial disease, venous thromboembolism and related complications like heart failure.

The selected medicines of interest are part of the WHO essential medicines list for treatment of chronic diseases in LMICs [24] and are recommended in the management of DM and CVD by the 2012 Uganda clinical guidelines [25], the 2017 American Diabetes Association guidelines of standard of care of DM and related CVD [22] and the recent European Society of Cardiology (ESC) guidelines of management of atrial fibrillation, acute myocardial infarction, acute heart failure [26-29].

The respective medicine categories and medicines of interest were oral hypoglycaemic agents (OHA) which included metformin $1 \mathrm{~g}$ and $500 \mathrm{mg}$, glibenclamide $5 \mathrm{mg}$, glimepiride $2 \mathrm{mg}$ and pioglitazone $30 \mathrm{mg}$, angiotensin II receptor blockers (ARB) which included losartan $50 \mathrm{mg}$ and telmisartan $40 \mathrm{mg}$, angiotensin converting enzyme inhibitors (ACEI) which included captopril $25 \mathrm{mg}$, thiazide diuretics (D) which included bendrofluazide $5 \mathrm{mg}$, ARB-D which included losartan-hydrochlorothiazide 50/12.5 mg and telmisartan-hydrochlorothiazide 40/12.5 mg, loop diuretics which included oral furosemide $40 \mathrm{mg}$ and i.v. furosemide $20 \mathrm{mg}$, calcium channel blockers (CCB) which included nifedipine $10 \mathrm{mg}$ and $20 \mathrm{mg}$ and amlodipine $5 \mathrm{mg}$ and $10 \mathrm{mg}$, statins which included simvastatin $20 \mathrm{mg}$, atovastatin $20 \mathrm{mg}$ and rosuvastatin $10 \mathrm{mg}$, anti platelet drugs which included cardiac aspirin $75 \mathrm{mg}$ and Clopidogrel $75 \mathrm{mg}$, low molecular weight heparin which included enoxaparin $60 \mathrm{mg}$ and $80 \mathrm{mg}$ and beta blockers which included atenolol $50 \mathrm{mg}$, bisoprolol $5 \mathrm{mg}$, nebivolol $5 \mathrm{mg}$ and carvedilol $6.25 \mathrm{mg}$. Other surveyed medicines included: parenteral benzathine penicillin, oral digoxin, warfarin, spironolactone, hydralazine, soluble insulin, intermediate insulin, pre mixed insulin, isosorbide mononitrate and unfractionated heparin (UFH).

The selected diagnostic tests are part of the WHO minimum workup tests for assessment and management of cardiovascular (CV) risk [24] and are also recommended by the 2017 American Diabetes Association guidelines of standard of care of DM and related CVD [22] and the recent European Society of Cardiology (ESC) guidelines of management of atrial fibrillation, acute myocardial infarction, acute heart failure [26-29]. These included: lipid profile, glycated haemoglobin (HbA1c), serum uric acid, serum troponin, coagulation profile, thyroid function tests, serum creatinine, serum urea, serum electrolytes, serum ketones, microalbuminuria, complete blood count, serum natriuretic peptides, electrocardiography (ECG), echocardiography (ECHO), chest $\mathrm{X}$ ray, liver function tests and urinalysis.

Data was collected using a pre tested questionnaire based on the WHO and HAI standardised methods of assessing medicine prices, availability and affordability in LMIC [21] from 15th January 2017 to 28th February 2017. The data collection team underwent a brief training before commencement of the study to improve quality and standardisation of data.

Information about the availability of diagnostic tests and any medicine in the respective medicine category was obtained. The cost of performing each diagnostic test and the monthly cost of the recommended dose of the available lowest priced generic (LPG) medicine was obtained in Uganda shillings (UgX) and then converted to US dollars (USD) using the existing exchange rate at the time of data collection ( 1 USD $=3600 \mathrm{UgX}$ ). The obtained costs of the medicines were the retail prices charged directly to the patients at the respective pharmacies of the private hospitals and private pharmacies. The cost of the medicines in the public hospitals was not obtained since medical care is offered free of charge.

\section{Data analysis}

Availability of the medicines and diagnostic tests was assessed by calculating the proportion of hospitals and 
private pharmacies in which any desired dose of the medicine and diagnostic test was present on the day of data collection at the study site. We defined availability as low, moderate or high when the medicines and diagnostic tests of interest were available in $<50,50-79$ and $\geq 80 \%$ of the study sites respectively. Availability of the selected medicines and diagnostic tests was compared between the study sites to determine any statistically significant difference which was defined as a $p$ value of $<0.05$. The cost of the available LPG medicine was compared to the cost of the available originator medicine.

The obtained unit retail prices of the medicines in USD were converted to a median price ratio (MPR) by dividing the median local price by an international reference price (IRP). The IRP is obtained from the Management Sciences for Health International Drug Price Indicator Guide which reports median prices of high quality multisource medicines offered to LMIC countries by different suppliers. The MPR is used to express how much greater or less the median local medicine price is than the IRP. An MPR of 3 would mean that the local medicine price is three times greater than the IRP. For patients' medicine prices, MPR $\leq 1.5$ were considered reasonable pricing [30].

Affordability was estimated by calculating the number of days' wages required to purchase a one month course of treatment or pay for a specific diagnostic test using the average salary of the lowest paid government worker in USD. Medicines and diagnostic tests that cost $\leq 3$ days' wages were considered affordable. The exchange rate of the local currency (UgX) to USD used was the commercial "buy" rate at the time of data collection of 1 USD $=3600 \mathrm{UgX}$. The lowest paid government worker at the time of the study (scale U8 lower-non formal education teachers) earned a gross salary of 198,793 UgX (USD 55.2). After tax deductions, this translated to a net salary of $139,155 \mathrm{UgX}$ (USD 38.7) per month or 4638.5 UgX (1.3 USD) daily [31].

\section{Results}

\section{Availability of the medicines}

Low, moderate and high availability was documented in 5 (23.8\%), 3 (14.3\%) and 13 (61.9\%) of the 21 surveyed medicines categories respectively. The availability of the surveyed medicine categories ranged from $20.1 \%$ for unfractionated heparin (UFH) to $100 \%$ for OHA. High availability was noted for the majority of the key medicine categories in the management of hypertension and cardiac diseases i.e. ARBs, ACEI, D, CCB, statins, anti platelet drugs and beta blockers. None of the insulin types was of high availability. Soluble, intermediate and pre mixed insulin was available in $68.8,34.7$ and $60.1 \%$ of all the study sites respectively. Isosorbide nitrate, UFH and LMWH were all of low availability (summarised in Table 1).

\section{Availability of the diagnostic tests}

With regard to the 19 diagnostic tests of interest, 8 (42.1\%) were of low availability, 3 (15.8\%) were of moderate availability and 8 (42.1\%) were of high availability. The availability ranged from $6.8 \%$ for microalbuminuria to $100 \%$ for urinalysis. Apart from electrocardiography (ECG) and lipid profile testing which were available in only 54.6 and $65.9 \%$ of the study hospitals, the rest of the recommended WHO minimum tests for DM and CVD workup were of high availability (random blood glucose tests-97.7\%, serum electrolytes- $88.6 \%$ and urinalysis-100\%). Glycated haemoglobin (HbA1c) tests, a key test in DM diagnosis and monitoring of glycaemic control in diabetes care was available in only $43.2 \%$ of the study hospitals. The majority of vital tests in cardiac evaluation (echocardiography, coagulation profile, serum natriuretic peptides and troponin tests) were of low availability (summarised in Table 1).

\section{Comparison of the availability of selected medicines in the different study sites}

There were significant differences in the availability of key medicines documented in the public hospitals and the private hospitals and pharmacies. Low availability was noted for these medicine categories in public hospitals compared to the private hospitals and pharmacies: ARBs, ARB-thiazide diuretics, statins, warfarin, LMWH, UFH and nitrates (summarised in Table 2).

Comparison of the availability of selected diagnostic tests in public and private hospitals

With regard to the diagnostic tests, a statistically significant difference in the availability of lipid profile, HbA1c, uric acid, troponin, coagulation profile and thyroid function tests was noted in the surveyed public hospitals compared to the private hospitals. All the documented tests were of low availability in the public hospitals. Tests for serum ketones, microalbuminuria, serum natriuretic peptides and $\mathrm{ECHO}$ were of low availability regardless of the study site (summarised in Table 3).

\section{Affordability of the study medicines and diagnostic tests of interest \\ Selected medicines}

The only affordable medicines were parenteral benzathine penicillin $2.4 \mathrm{MU}$ ( 0.3 days' wages), oral furosemide $40 \mathrm{mg}$ (0.5 days' wages), glibenclamide $5 \mathrm{mg}$ (0.7 days' wages), bendrofluazide $5 \mathrm{mg}$ ( 0.7 days' wages), atenolol $50 \mathrm{mg}$ (0.7 days' wages), cardiac aspirin $75 \mathrm{mg}$ (0.9 days' wages), digoxin $0.25 \mathrm{mg}$ (1.4 days' wages), metformin $500 \mathrm{mg}$ (2.8 days' wages), captopril $25 \mathrm{mg}$ (2.8 days' wages) and nifedipine $20 \mathrm{mg}$ (2.8 days' wages). The most unaffordable medicines were enoxaparin $80 \mathrm{mg}$ (53.5 days' wages), enoxaparin $60 \mathrm{mg}$ (41.2 days' wages) and UFH (38.5 days' wages). 
Table 1 Availability of all the DM and CVD medicines and diagnostic tests in all the study sites

\begin{tabular}{|c|c|c|c|}
\hline Medicines ( $N=21$ classes) & Availability (\%) & Diagnostic tests $(N=19)$ & Availability (\%) \\
\hline UFH & 20.1 & Microalbuminuria & 6.8 \\
\hline Isosorbide mono nitrate & 27.8 & Serum ketones & 11.4 \\
\hline LMWH & 31.9 & Serum natriuretic peptides & 11.4 \\
\hline Intermediate insulin & 34.7 & Echocardiography & 34.1 \\
\hline Hydralazine & 47.2 & Coagulation profile & 36.4 \\
\hline Pre mixed insulin & 60.1 & Serum troponin testing & 43.2 \\
\hline Warfarin & 64.6 & $\mathrm{HbA} 1 \mathrm{c}$ testing & 43.2 \\
\hline Soluble insulin & 68.8 & Thyroid function tests & 43.2 \\
\hline ARB-thiazide diuretics & 82.6 & Electrocardiography & 54.6 \\
\hline Digoxin & 84.0 & Uric acid testing & 56.8 \\
\hline Statins & 84.0 & Lipid profile & 65.9 \\
\hline ARB & 86.8 & Creatinine & 86.4 \\
\hline Spironolactone & 87.5 & Urea & 86.4 \\
\hline Benzathine penicillin & 87.5 & Serum electrolytes & 88.6 \\
\hline Furosemide & 89.6 & Chest X-ray & 88.6 \\
\hline Thiazide diuretics & 94.4 & Liver function tests & 95.5 \\
\hline Anti platelet drugs & 95.1 & Glucometers & 97.7 \\
\hline ACEI & 96.5 & CBC testing & 97.7 \\
\hline Beta blockers & 97.2 & Urinalysis & 100 \\
\hline CCB & 99.3 & & \\
\hline $\mathrm{OHA}$ & 100 & & \\
\hline
\end{tabular}

UFH Unfractionated heparin, $L M W H$ Low molecular weight heparin, $A R B$ Angiotensin II receptor blockers, $A C E I$ Angiotensin converting enzyme inhibitors, $C C B$ Calcium channel blockers, $\mathrm{OHA}$ Oral hypoglycaemic agents, HbA1c Glycated haemoglobin

Monthly management of an adult diabetic patient with the cheapest oral hypoglycaemic agents (Glibenclamide $5 \mathrm{mg}$ and metformin $500 \mathrm{mg}$ ), ACEI (captopril $25 \mathrm{mg}$ ), statin (simvastatin $20 \mathrm{mg}$ ) and anti platelet drug (cardiac aspirin $75 \mathrm{mg}$ ) would cost a total of $15.8 \mathrm{USD}$; equivalent to 12.2 days' wages. The monthly cost increased to 19.1 USD or 14.7 days' wages if glimepiride, a newer generation sulphonylurea was used or to 21.3 USD or 16.4 days' wages if pre mixed insulin was used instead of a sulphonylurea.

Management of hypertension co-morbidity by adding the cheapest CCB (nifedipine $20 \mathrm{mg}$ ) would cost 19.4 USD or 14.9 days' wages. Secondary prevention of CVD using the cheapest selective beta blocker (bisoprolol $5 \mathrm{mg}$ ), ACEI (captopril $25 \mathrm{mg}$ ), statin (simvastatin $20 \mathrm{mg}$ ) and anti platelet drug (cardiac aspirin $75 \mathrm{mg}$ ) would cost a total of 18.3 USD per month which is equivalent to 14.1 days' wages (summarised in Table 4).

Median cost, pricing of the available LPG medicines and their comparison with the available originator medicines With regard to pricing as reflected by the MPR, the only reasonably priced medicines were parenteral benzathine penicillin (1.2), losartan $50 \mathrm{mg}$ (0.8) and amlodipine $10 \mathrm{mg}$ (1.5). The MPR ranged from 0.8 for losartan $50 \mathrm{mg}$ to 11.1 for simvastatin (summarised in Table 4).
With the exception of Glucophage ${ }^{\bullet}$ (metformin) $1 \mathrm{~g}$, Insulitard $^{\circ}$ (intermediate insulin) and Mixtard $^{\circ}$ (pre mixed insulin), all of the available originator medicine brands cost more than the available LPG medicine brands. One originator brand (Adalat $30 \mathrm{mg}$ ) cost up to 10 times the cost of the available LPG brand (nifedipine $20 \mathrm{mg}$ ) (summarised in Table 5).

\section{Selected diagnostic tests}

The only affordable tests were random blood glucose measurement (1.1 days' wages), urinalysis (1.3 days' wages), serum ketone measurement (2.1 days' wages), serum uric acid measurement (2.1 days' wages), serum creatinine measurement (2.4 days' wages) and serum urea measurement (2.4 days' wages). The most unaffordable diagnostic tests were echocardiography and serum natriuretic peptides that cost 33.1 and 40.6 days' wages respectively.

The cost of performing the WHO recommended tests for $\mathrm{CV}$ risk assessment and management (proteinuria, ECG, FBG, lipid profile and serum electrolytes measurement) was 33.5 USD or 25.8 days' wages if urinalysis was used. The cost increased to 44.3 USD or 34.1 days' wages if microalbuminuria was used instead of urinalysis. The WHO CV risk monitoring tests (lipid profile, FBG and 
Table 2 Comparison of the availability of the DM and CVD medicines between the public hospitals, private hospitals and pharmacies

\begin{tabular}{|c|c|c|c|c|}
\hline \multicolumn{5}{|c|}{ Availability of the medicines in \% } \\
\hline Medicines & Private hospitals $(n=23)$ & Public hospitals $(n=22)$ & Private pharmacy $(n=100)$ & $P$ value \\
\hline \multicolumn{5}{|c|}{ A: Medicines with a statistically significant difference between study sites } \\
\hline ARBs & 87.0 & 31.8 & 99.0 & $<0.001$ \\
\hline ARB-thiazide diuretics & 78.3 & 27.3 & 96.0 & $<0.001$ \\
\hline Statins & 87.0 & 18.2 & 98.0 & $<0.001$ \\
\hline Warfarin & 65.2 & 18.2 & 74.8 & $<0.001$ \\
\hline Soluble insulin & 100 & 81.8 & 58.6 & $<0.001$ \\
\hline Thiazide diuretics & 82.6 & 95.5 & 97.0 & 0.025 \\
\hline Spironolactone & 91.3 & 68.2 & 90.9 & 0.012 \\
\hline LMWH & 47.8 & 9.1 & 33.3 & 0.018 \\
\hline UFH & 39.1 & 4.6 & 19.2 & 0.014 \\
\hline Isosorbide mono nitrate & 30.4 & 4.6 & 32.3 & 0.030 \\
\hline \multicolumn{5}{|c|}{ B: Medicines with no statistically significant difference between study sites } \\
\hline Captopril & 91.3 & 95.5 & 98.0 & 0.277 \\
\hline$C C B$ & 95.7 & 100 & 100 & 0.071 \\
\hline Beta blockers & 95.6 & 100 & 97.0 & 0.650 \\
\hline Anti platelet drugs & 91.3 & 91.0 & 97.0 & 0.317 \\
\hline Digoxin & 91.3 & 81.2 & 82.3 & 0.579 \\
\hline Pre mixed insulin & 69.6 & 77.3 & 54.1 & 0.080 \\
\hline Intermediate insulin & 43.5 & 27.3 & 34.3 & 0.516 \\
\hline Benzathine penicillin & 91.3 & 100 & 83.8 & 0.097 \\
\hline Loop duiretics & 91.3 & 100 & 86.9 & 0.182 \\
\hline Hydralazine & 65.2 & 45.6 & 43.4 & 0.166 \\
\hline $\mathrm{OHA}$ & 100 & 100 & 100 & 1 \\
\hline
\end{tabular}

UFH Unfractionated heparin, LMWH Low molecular weight heparin, ARB Angiotensin II receptor blockers, $A C E$ Angiotensin converting enzyme inhibitors, CCB Calcium channel blockers, OHA Oral hypoglycaemic agents

proteinuria) cost 23.6 USD/18.2 days' wages or 12.8 USD/7.1 days' wages when using microalbuminuria or urinalysis respectively. Annual monitoring of adult diabetic patients using $\mathrm{HbA1c}$ measurement at least twice a year, annual ECG, microalbuminuria and lipid profile assessment as recommended by the ADA guidelines of diabetes management would cost 58.2 USD or 44.8 days' wages (summarised in Table 6).

\section{Discussion}

The ACCODAD study sought to provide contemporary data about the availability, cost and affordability of medicines and diagnostic tests integral in the management of DM and CVD in Uganda, a low income developing country in East Africa. To the best of our knowledge, this is the largest study in Uganda to comprehensively investigate the availability, cost and affordability of a substantial number of medicines and diagnostic tests that play a fundamental role in optimal DM and CVD management in clinical practice.

\section{Availability of medicines and diagnostic tests}

In our study, low and moderate availability (availability of $<80 \%$ in all study sites) was reported in $38.1 \%$ of the medicines and $57.9 \%$ of the diagnostic tests of interest. Several similar studies assessing access to medicines and diagnostic tests of NCDs in LMIC have reported similar findings of low availability of medicines and diagnostic tests especially in the public sector [5-10].

In the study reported from Western Cameroon, high availability defined as availability $\geq 80 \%$ was only noted with $6(27 \%)$ of the surveyed medicines (parenteral benzathine penicillin 2.4 MU, oral furosemide $40 \mathrm{mg}$, glibenclamide $5 \mathrm{mg}$, Actrapid/soluble insulin, metformin $500 \mathrm{mg}$ and Mixtard). The majority of rural study sites had low availability of medicines [6]. In comparison with our study, with the exception of the soluble and pre mixed insulin, high availability of $>80 \%$ was documented with parenteral benzathine penicillin, oral furosemide, glibenclamide and metformin. 
Table 3 Comparison of the availability of the DM and CVD diagnostic tests between the private and public hospitals

\begin{tabular}{|c|c|c|c|}
\hline \multicolumn{4}{|l|}{ Availability of the tests (\%) } \\
\hline Test & Private hospitals $(n=23)$ & Public hospitals $(n=24)$ & $P$ value \\
\hline \multicolumn{4}{|c|}{ A: Diagnostic tests with a statistically significant difference between study sites } \\
\hline Lipid profile & 86.4 & 45.5 & 0.004 \\
\hline $\mathrm{HbA1c}$ & 63.6 & 22.7 & 0.006 \\
\hline Uric acid & 77.3 & 36.4 & 0.006 \\
\hline Serum troponin & 68.2 & 18.2 & 0.001 \\
\hline Coagulation profile & 59.1 & 13.6 & 0.002 \\
\hline Thyroid function tests & 72.7 & 13.6 & $<0.001$ \\
\hline \multicolumn{4}{|c|}{ B: Diagnostic tests with no statistically significant difference between study sites } \\
\hline Serum creatinine & 95.5 & 77.3 & 0.079 \\
\hline Serum urea & 95.5 & 77.3 & 0.079 \\
\hline Glucometers & 100 & 95.5 & 0.312 \\
\hline Serum electrolytes & 95.5 & 81.8 & 0.154 \\
\hline Serum ketones & 13.6 & 9.1 & 0.635 \\
\hline Microalbuminuria & 4.6 & 9.1 & 0.550 \\
\hline $\mathrm{CBC}$ & 95.5 & 100 & 0.312 \\
\hline Serum natriuretic peptides & 18.2 & 4.6 & 0.154 \\
\hline Echocardiography & 45.5 & 22.7 & 0.112 \\
\hline Chest X-ray & 95.5 & 81.8 & 0.154 \\
\hline Liver function tests & 100 & 90.9 & 0.148 \\
\hline Electrocardiography & 54.5 & 54.5 & 1 \\
\hline Urinalysis & 100 & 100 & NA \\
\hline
\end{tabular}

HbA1c Glycated haemoglobin, CBC Complete blood count

In another study that assessed the availability, pricing and affordability of 5 key cardiovascular medicines (atenolol, captopril, hydrochlorothiazide, losartan and nifedipine) in 36 LMIC (Uganda inclusive), upper middle income and high income countries found an overall poor availability of these medicines. Only 26.3 and $57.3 \%$ of the medicines were available in the public and private sector respectively [7]. In another similar multicentre study involving 90 primary care facilities in 8 LMIC, some of the 12 surveyed CVD and DM medicines were not available in some countries. Soluble and long acting insulin was absent in all study sites in Benin, Eriteria, Bhutan and Vietnam. Isosorbide mono nitrate was absent in Benin, Eriteria, Sudan and Bhutan and simvastatin and amlodipine were absent in Eriteria and Bhutan [10]. Low availability of nitrates, intermediate and pre-mixed insulin was also reported by our study (27.8, 34.7 and $60.1 \%$ respectively).

With regard to the availability of diagnostic tests, cross sectional studies in LMIC had reported similar findings of low availability [5-9]. In one of these studies performed in the Western Cameroon in 2012, high availability defined as availability $\geq 80 \%$ was only noted with
$50 \%$ of the surveyed diagnostic tests (RBG, urinalysis, serum creatinine, serum urea and $\mathrm{CBC}$ ). Serum electrolytes, lipid profile and uric acid tests, $\mathrm{HbA} 1 \mathrm{c}$ tests and ECG were only available in $60,40,20$ and $10 \%$ of all the study sites [6].

Another multicentre study performed in 90 primary care centres of 8 LMIC (Benin, Bhutan, Eritrea, Sri Lanka, Sudan, Suriname, Syria, and Vietnam), lipid profile testing was available only in 33, 25, 20, 14 and $8 \%$ of all study sites in Sudan, Benin, Suriname, Syria and Sri Lanka. Low availability of serum creatinine tests was also reported in the majority of the study sites. Of all study sites, serum creatinine tests were available in $58 \%$ in Sudan, $33 \%$ in Benin, $10 \%$ in Suriname and $8 \%$ in Sri Lanka. Lipid profile tests were absent in Eriteria and Vietnam while serum creatinine tests were absent in all study sites in Eriteria, Bhutan and Syria. Serum troponin tests were absent in all the countries except Benin and Sudan where it was available in only $8 \%$ of the study sites [10].

Comparing with our study, we also reported similar findings of low availability of uric acid, HbA1c, ECG and troponin tests (all $<60 \%$ ). 
Table 4 Median prices and affordability of the DM-CVD lowest priced generic drugs in both private hospitals and pharmacies

\begin{tabular}{|c|c|c|c|c|c|c|}
\hline Medicine $(N=37)$ & $\begin{array}{l}\text { Median (IQR) price/tab } \\
\text { in Ug Shs }\end{array}$ & $\begin{array}{l}\text { Median price/tab } \\
\text { in USD }\end{array}$ & IRP in USD & MPR & $\begin{array}{l}\text { Monthly cost } \\
\text { in USD }\end{array}$ & Days' wages $^{c}$ \\
\hline \multicolumn{7}{|c|}{ A: Affordable drugs according to calculated days' wages $(\leq 3)$} \\
\hline Benzathine penicillin $2.4 \mathrm{MU}$ & $1500(1500-2000)$ & 0.42 & 0.3241 & 1.2 & 0.4 & 0.3 \\
\hline Furosemide tablet $40 \mathrm{mg}$ & $100(100-100)$ & 0.02 & 0.0061 & 3.3 & 0.6 & 0.5 \\
\hline Glibenclamide 5 mg & $100(100-200)$ & 0.03 & 0.0042 & 7.1 & 0.9 & 0.7 \\
\hline Bendrofluazide $5 \mathrm{mg}$ & $100(100-100)$ & 0.03 & 0.0072 & 4.2 & 0.9 & 0.7 \\
\hline Atenolol $50 \mathrm{mg}$ & $100(100-200)$ & 0.03 & 0.0106 & 2.8 & 0.9 & 0.7 \\
\hline Cardiac aspirin 75 mg & $150(150-200)$ & 0.04 & 0.0196 & 2.0 & 1.2 & 0.9 \\
\hline Digoxin tablet 0.25 mg & $200(200-300)$ & 0.06 & 0.0148 & 4.1 & 1.8 & 1.4 \\
\hline Metformin 500 mg & $200(200-300)$ & 0.06 & 0.0168 & 3.6 & 3.6 & 2.8 \\
\hline Captopril 25 mg & $200(200-300)$ & 0.06 & 0.0216 & 2.8 & 3.6 & 2.8 \\
\hline Nifedipine 20 mg & $200(100-250)$ & 0.06 & 0.0233 & 2.6 & 3.6 & 2.8 \\
\hline \multicolumn{7}{|c|}{ B: Unaffordable drugs according to the calculated days' wages (> 3) } \\
\hline Amlodipine $5 \mathrm{mg}$ & $500(400-500)$ & 0.14 & 0.0321 & 4.4 & 4.2 & 3.2 \\
\hline Warfarin $5 \mathrm{mg}$ & $500(500-500)$ & 0.14 & 0.0369 & 3.8 & 4.2 & 3.2 \\
\hline Glimepiride 2 mg & $500(400-1000)$ & 0.14 & - & - & 4.2 & 3.2 \\
\hline Spironolactone $25 \mathrm{mg}$ & $500(400-600)$ & 0.14 & 0.0398 & 3.5 & 4.2 & 3.2 \\
\hline Furosemide i.v vial 20 mg & $1000(1000-1500)$ & 0.28 & 0.0623 & 4.5 & 4.2 & 3.2 \\
\hline Hydralazine tablet 25 mg & $300(225-450)$ & 0.08 & 0.0376 & 2.1 & 4.8 & 3.7 \\
\hline Telmisartan 40 mg & $600(500-800)$ & 0.17 & - & - & 5.1 & 3.9 \\
\hline Bisoprolol 5 mg & $600(500-800)$ & 0.17 & - & - & 5.1 & 3.9 \\
\hline Pioglitazone 30 mg & $600(500-800)$ & 0.17 & - & - & 5.1 & 3.9 \\
\hline Losartan 50 mg & $700(600-800)$ & 0.19 & 0.2443 & 0.8 & 5.7 & 4.4 \\
\hline Soluble insulin 1vial & $22,000(20000-25,000)$ & 6.11 & 0.7723 & 7.9 & 6.1 & 4.7 \\
\hline Amlodipine 10 mg & $750(700-800)$ & 0.21 & 0.1414 & 1.5 & 6.3 & 4.9 \\
\hline Intermediate insulin 1 vial & $23,000(20000-25,000)$ & 6.39 & 0.7723 & 8.3 & 6.4 & 4.9 \\
\hline Pre mixed insulin 1vial & $23,000(21000-25,000)$ & 6.39 & 0.6143 & 10.4 & 6.4 & 4.9 \\
\hline Clopidogrel 75 mg & $800(700-1100)$ & 0.22 & 0.0736 & 3.0 & 6.6 & 5.1 \\
\hline Losartan H 62.5 mg & $800(700-900)$ & 0.22 & - & - & 6.6 & 5.1 \\
\hline Telmisartan H 52.5 mg & $800(700-1000)$ & 0.22 & - & - & 6.6 & 5.1 \\
\hline Nebivolol 5 mg & $1000(900-1300)$ & 0.28 & - & - & 8.4 & 6.5 \\
\hline Simvastatin $20 \mathrm{mg}$ & $1000(900-1500)$ & 0.28 & 0.0252 & 11.1 & 8.4 & 6.5 \\
\hline Isosorbide mono-nitrate $10 \mathrm{mg}$ & $1000(985-1600)$ & 0.28 & 0.0705 & 4.0 & 8.4 & 6.5 \\
\hline Atovastatin $20 \mathrm{mg}$ & $1200(1000-2000)$ & 0.33 & 0.0640 & 5.2 & 9.9 & 7.6 \\
\hline Rosuvastatin $10 \mathrm{mg}$ & $1200(1000-2000)$ & 0.33 & - & - & 9.9 & 7.6 \\
\hline Carvedilol 6.25 mg & $700(600-900)$ & 0.19 & 0.0445 & 4.3 & 11.4 & 8.8 \\
\hline Metformin 1000 mg & $700(500-800)$ & 0.19 & - & - & 11.4 & 8.8 \\
\hline $\mathrm{UFH}^{\mathrm{b}} 5000$ units & $20,000(18000-20,000)$ & 5.56 & 0.9055 & 6.1 & 50.0 & 38.5 \\
\hline $\mathrm{LMWH}^{\mathrm{a}} 60 \mathrm{mg}$ & $38,500(34500-45,000)$ & 10.69 & 2.8751 & 3.7 & 53.5 & 41.2 \\
\hline $\mathrm{LMWH}^{\mathrm{a}} 80 \mathrm{mg}$ & $50,000(45000-60,000)$ & 13.89 & 5.8025 & 2.4 & 69.5 & 53.5 \\
\hline
\end{tabular}

IQR Inter-quartile range, ${ }^{\mathrm{a}} \mathrm{LMWH}$ Low molecular weight heparin, ${ }^{\mathrm{b}} \mathrm{UFH}$ Unfractionated heparin

'Days' wages-number of days' wages to cover the monthly costs of the selected drug 
Table 5 Comparison between the median prices of the originator and lowest priced generic medicines

\begin{tabular}{|c|c|c|c|c|c|}
\hline Originator medicine (OM) & $\begin{array}{l}\text { Median (IQR) price } \\
\text { of OM in UgX }\end{array}$ & $\begin{array}{l}\text { Median (IQR) price } \\
\text { of OM in USD }\end{array}$ & Name of LPG medicine & $\begin{array}{l}\text { Median (IQR) of the } \\
\text { LPG medicine (UgX) }\end{array}$ & $\begin{array}{l}\text { Median (IQR) price } \\
\text { of LPG in USD }\end{array}$ \\
\hline Micardis $40 \mathrm{mg}$ & $3700(2000-4000)$ & $1.0(0.6-1.1)$ & Telmisartan 40 mg & $600(500-800)$ & $0.2(0.1-0.2)$ \\
\hline Co-Micardis 40/12.5 mg & $4000(2000-4500)$ & $1.1(0.6-1.3)$ & Telmisartan-H & $800(700-1000)$ & $0.2(0.2-0.3)$ \\
\hline Adalat 30 mg & $2000(1500-2500)$ & $0.6(0.5-0.7)$ & Nifedipine $20 \mathrm{mg}$ & $200(100-250)$ & $0.1(0.02-0.1)$ \\
\hline Norvasc 5 mg & $1000(1000-2600)$ & $0.3(0.3-0.7)$ & Amlodipine 5 mg & $500(400-500)$ & $0.1(0.1-0.1)$ \\
\hline Norvasc 10 mg & $1500(1250-2800)$ & $0.4(0.3-0.8)$ & Amlodipine 10 mg & $750(700-800)$ & $0.2(0.2-0.2)$ \\
\hline Concor 5 mg & $2500(1800-2500)$ & $0.7(0.5-0.7)$ & Bisoprolol 5 mg & $600(500-800)$ & $0.2(0.1-0.2)$ \\
\hline Lipitor 20 mg & $3000(2000-4000)$ & $0.8(0.6-1.1)$ & Atovastatin 20 mg & $1200(1000-2000)$ & $0.3(0.3-0.6)$ \\
\hline Crestor 10 mg & $3000(2500-3500)$ & $0.8(0.7-1)$ & Rosuvastatin $10 \mathrm{mg}$ & $1200(1000-2000)$ & $0.3(0.3-0.6)$ \\
\hline Bayer aspirin 100 mg & $400(300-500)$ & $0.1(0.1-0.1)$ & Cardiac aspirin 75 mg & $150(150-200)$ & $0.04(0.04-0.1)$ \\
\hline Glucophage 500 mg & $400(300-500)$ & $0.1(0.1-0.1)$ & Metformin 500 mg & $200(200-300)$ & $0.1(0.1-0.1)$ \\
\hline Glucophage 1000 mg & $600(525-800)$ & $0.2(0.2-0.2)$ & Metformin 1000 mg & $700(500-800)$ & $0.2(0.1-0.2)$ \\
\hline Amaryl 2 mg & $1800(1000-2000)$ & $0.5(0.3-0.6)$ & Glimepiride 2 mg & $500(400-1000)$ & $0.1(0.1-0.3)$ \\
\hline Actrapid 1 vial & $23,000(22000-25,000)$ & $6.4(6.1-6.9)$ & Soluble insulin 1 vial & $22,000(20000-25,000)$ & $6.1(5.6-6.9)$ \\
\hline Insulitard 1 vial & $23,000(22000-25,000)$ & $6.4(6.1-6.9)$ & Intermediate insulin & $23,000(20000-25,000)$ & $6.4(5.6-6.9)$ \\
\hline Mixtard 1 vial & $23,000(22000-25,000)$ & $6.4(6.1-6.9)$ & Pre mixed insulin & $23,000(21000-25,000)$ & $6.4(5.8-6.9)$ \\
\hline Clexane 60 mg & $42,000(35000-46,800)$ & $11.7(9.7-13)$ & LMWH 60 mg & $38,500(34500-45,000)$ & $10.7(9.6-12.5)$ \\
\hline Clexane 80 mg & $60,000(55000-69,000)$ & $16.7(15.3-19.2)$ & LMWH 80 mg & $50,000(45000-60,000)$ & $13.9(12.5-16.7)$ \\
\hline
\end{tabular}

OM Originator medicine, LPG Lowest priced generic, IQR Inter-quartile range, LMWH Low molecular weight heparin, UgX Uganda shillings, USD US dollars

\section{Affordability of medicines and diagnostic tests of interest} The majority of surveyed medicines and diagnostic tests have also been reported to be unaffordable in most studies in LMIC, similar to the findings of our study. Our study findings documented that only $27 \%$ of the surveyed medicines and $32 \%$ of the surveyed diagnostic tests were affordable in Uganda.

In comparison, only 7 (32\%) of the studied medicines (oral aspirin $500 \mathrm{mg}$, hydrochlorothiazide $50 \mathrm{mg}$, furosemide $40 \mathrm{mg}$, nifedipine 10 and $20 \mathrm{mg}$, glibenclamide $5 \mathrm{mg}$ and metformin $500 \mathrm{mg}$ ) were affordable according to the study definition of affordability i.e. monthly cost of a medicine of $\leq 1$ days' wages of a lowest paid public servant in the study performed in Western Cameroon [6]. The most unaffordable medicines in this study were Mixtard, simvastatin $20 \mathrm{mg}$ and heparin $5000 \mathrm{IU}$ costing 18.7 days' wages, 30.5 days' wages and 182.36 days' wages respectively [6]. In our study, only 6 (16\%) medicines cost less than a days' wages (parenteral benzathine penicillin, oral furosemide, glibenclamide, bendrofluazide, atenolol, and cardiac aspirin).

In another multicentre study by Mendis $S$ et al. in 6 LMIC (Bangladesh, Malawi, Sri Lanka, Brazil, Nepal and Pakistan) assessing availability and affordability of 32 medicines essential in CVD, DM, asthma, glaucoma and palliative care, anti hypertensive management using hydrochlorothiazide monotherapy and glycaemic therapy using either glibenclamide or metformin was affordable in all the 6 countries (cost $\leq 1$ days' wages). Using intermediate insulin for DM management was unaffordable with a monthly cost equivalent to 2.8 days' wages in Brazil, 4.7 days' wages in Pakistan, 6.1 days' wages in Sri Lanka, 7.3 days' wages in Nepal and 19.6 days' wages in Malawi. Secondary prevention of CVD with an oral aspirin, statin, beta blocker and ACEI in this study was also unaffordable in some countries. This combination using a generic medicine would cost $\leq 1.6$ days' wages in Sri Lanka and Bangladesh, $\leq 6.1$ days' wages in Brazil, Pakistan and Nepal and 18.4 days' wages in Malawi. The cost of treatment in Malawi would increase to 48.8 days' wages if an innovator statin brand was used [5]. In our study, the monthly cost of combination therapy used in secondary CVD prevention using the cheapest beta blocker, ACEI, statin and cardiac aspirin was 14.1 days' wages; almost similar to the cost in Malawi.

Regarding diagnostic tests, only urinalysis and random blood glucose tests cost less than 1.5 days' wages in the study by Jingi A et al. in Western Cameroon. Other key tests recommended by the WHO in optimal DM and CVD workup in this study like lipid profile tests cost 3.1-3.6 days' wages and ECG cost 10.7 days' wages. Glycated haemoglobin (HbA1c), an important test in diagnosis and monitoring of glycaemic control in diabetes care cost 12.6 days' wages [6]. Comparing to our study findings, serum electrolytes, lipid profile test, HbA1c test and ECG cost 5.3 days' wages, 7.5 days' wages, 8.6 days' wages and 10.7 days' wages respectively. 
Table 6 Cost and affordability of DM-CVD selected diagnostic/screening tests in the private hospitals

\begin{tabular}{|c|c|c|c|c|}
\hline Test & Median (IQR) price in UgX & Median price in USD & Monthly cost in USD & Days' wages for test \\
\hline \multicolumn{5}{|l|}{ A: Affordable diagnostic tests } \\
\hline RBG & $5000(5000-6950)$ & 1.4 & 1.4 & 1.1 \\
\hline Urinalysis & $6250(5000-10,000)$ & 1.7 & 1.7 & 1.3 \\
\hline Serum ketones & $10,000(10000-10,000)$ & 2.8 & 2.8 & 2.1 \\
\hline Serum uric acid & $10,000(10000-15,500)$ & 2.8 & 2.8 & 2.1 \\
\hline Serum urea & $11,000(10000-19,900)$ & 3.1 & 3.1 & 2.4 \\
\hline Serum creatinine & $11,000(10000-20,000)$ & 3.1 & 3.1 & 2.4 \\
\hline \multicolumn{5}{|l|}{ B: Unaffordable diagnostic tests } \\
\hline CBC & $15,000(13000-20,000)$ & 4.2 & 4.2 & 3.2 \\
\hline Serum electrolytes & $25,000(15000-30,000)$ & 6.9 & 6.9 & 5.3 \\
\hline Coagulation profile & $30,000(20000-30,000)$ & 8.3 & 8.3 & 6.4 \\
\hline Chest X-ray & $30,000(25000-45,000)$ & 8.3 & 8.3 & 6.4 \\
\hline Lipid profile & $35,000(30000-41,000)$ & 9.7 & 9.7 & 7.5 \\
\hline Liver function tests & $36,000(27500-47,850)$ & 10.0 & 10.0 & 7.7 \\
\hline Serum $\mathrm{HbA} 1 \mathrm{c}$ & $40,000(35000-40,000)$ & 11.1 & 11.1 & 8.6 \\
\hline Microalbuminuria & $45,000(45000-45,000)$ & 12.5 & 12.5 & 9.6 \\
\hline Electrocardiography & $50,000(40000-52,000)$ & 13.8 & 13.8 & 10.7 \\
\hline Serum troponin & $53,000(45000-60,000)$ & 14.7 & 14.7 & 11.3 \\
\hline Thyroid function tests & $100,000(77500-149,000)$ & 27.8 & 27.8 & 21.4 \\
\hline Echocardiography & $155,000(100000-175,000)$ & 43.1 & 43.1 & 33.1 \\
\hline Serum natriuretic peptides & $190,000(150000-275,000)$ & 52.8 & 52.8 & 40.6 \\
\hline
\end{tabular}

RBG Random blood glucose, CBC Complete blood count, HbA1c Glycated haemoglobin, UgX Uganda shillings, USD US dollars

There are several plausible explanations for the low availability of medicines and diagnostic tests especially in the public hospitals in our study. Some of these key medicines are not included in the 2012 national essential medicine list and the 2016 Uganda Clinical guidelines of management of NCDs. Inadequate allocation of funds to the health sector to enable procurement of most essential medicines and diagnostic tests, poor stock maintenance, forecast inaccuracy and inefficient distribution systems from the national central procurement institution could also explain the low availability in the public and private sectors.

The study finding of the majority of medicines and diagnostic tests being unaffordable in the private sector could be explained by the lack of local legislation to regulate the maximum retail prices of medicines and a vibrant local pharmaceutical industry sector to produce cheap quality generic medicines for chronic diseases.

\section{Conclusions}

The ACCODAD study evidently demonstrates that the majority of medicines and diagnostic tests important in DM and CVD care are largely unavailable and unaffordable in Uganda. These study findings offer contemporary information to guide pragmatic approaches to address the inequity in access to affordable medicines and diagnostic tests that are essential in DM and CVD care in Uganda. More emphasis should be directed towards improving access to these essential medicines and diagnostic tests in the public sector by ensuring their procurement by the mandated central procurement institution (NMS): ARBs, statins, warfarin, heparins, nitrates, lipid profile, $\mathrm{HbA1c}$, uric acid, troponin, coagulation profile and thyroid function tests.

Concerted efforts to reduce the cost of UFH, LMWH, new generation beta blockers, statins and insulin in the private sector should be encouraged. Generally, availability and affordability of these medicines and diagnostic tests can be improved in Uganda by improving procurement efficiency, stock handling, forecast accuracy, ensuring equitable financing to the health sector and regular updating of the national essential drug list and management guidelines. Strategies like boosting local pharmaceutical production of high quality generic DM and CVD medicines and introduction of local laws to regulate retail prices of medicines can assist in reducing the cost of these medicines. Due to the high costs of secondary and tertiary DM and CVD management, national policies to promote primary prevention strategies of NCD should be widely adopted. 


\section{Study limitations}

Being a point in time study, variations in availability, pricing and affordability of the medicines and diagnostic tests was not put into consideration. We were unable to obtain the procurement prices from the central procurement institution, NMS to obtain the prices of the medicines and diagnostic tests in the public hospitals. Using the daily wage of the lowest paid unskilled government to calculate affordability of medicines and diagnostic tests has its limitations because a significant proportion of the Ugandan population earns less than this amount. Despite these limitations, the study has its strengths. The standardised WHO/HAI methodology that was used has been widely validated.

\begin{abstract}
Abbreviations
ACCODAD: Access to Cardiovascular diseases, Chronic Obstructive pulmonary disease, Diabetes mellitus and asthma drugs and diagnostics; ACEl: Angiotensin converting enzyme inhibitors; ADA: American Diabetes Association; ARB: Angiotensin II receptor blockers; CCB: Calcium channel blockers; CD: Communicable diseases; CVD: Cardiovascular diseases; DM: Diabetes mellitus; ECG: Electrocardiography; ECHO: Echocardiography; ESC: European Society of Cardiology; FBG: Fasting blood glucose; HAl: Health Action International; HbA1c: Glycated haemoglobin; HT: Hypertension; IDF: International diabetes federation; IRP: International reference price; LMIC: Low and middle income countries; LPG: Lowest priced generic; MPR: Median price ratio; NCD: Non communicable diseases; NDA: National Drug Authority; NMS: National Medical Stores; OHA: Oral hypoglycaemic agents; UFH: Unfractionated heparin; UgX: Uganda shillings; USD: US dollars; WHO: World Health Organisation
\end{abstract}

\section{Acknowledgments}

We would like to recognise and thank the entire study data collection team and the Uganda Diabetes Association for offering the small grant that supported this research project.

\section{Funding}

This study was supported by a small grant from the Uganda Diabetes Association, a local professional association for diabetic patients in Uganda.

\section{Availability of data and materials}

The data set in form of an excel file supporting the results of this article is available when requested from the corresponding author.

\section{Authors' contributions \\ DK, DA, LK, DSK, PD, JN, RMM, RK and WL collectively contributed to the design of the study, data collection, drafting of the initial manuscript, appraisal and approval of the final submitted manuscript. DK and LK performed the statistical analysis.}

\section{Ethics approval and consent to participate}

Ethical approval to conduct this study was granted by the ethics review board of St. Francis hospital, Nsambya Uganda as mandated by the Uganda National Council of Science and Technology (UNCST).

\section{Consent for publication}

No individual person's data in any form (details, image and videos) was used in this manuscript.

\section{Competing interests}

DK works in the medical unit of GlaxoSmithKline (GSK) pharmaceutical Kenya Limited in Uganda. GSK did not participate in the study funding, design or analysis of the data. The views expressed in this manuscript are solely the author's (DK). The rest of the authors declare no competing interests.

\section{Publisher's Note}

Springer Nature remains neutral with regard to jurisdictional claims in published maps and institutional affiliations.

\section{Author details}

${ }^{1}$ Department of Medicine, Uganda Martyrs Hospital Lubaga, P.O.BOX 7146 Kampala, Uganda. ${ }^{2}$ Department of Medicine, Case Hospital Kampala, Kampala, Uganda. ${ }^{3}$ Infectious Disease Research Collaboration (IDRC), Kampala, Uganda. ${ }^{4}$ Nephrology unit, Mulago National Referral and Teaching Hospital, Kampala, Uganda. ${ }^{5}$ Department of Medicine, Lira Regional Referral Hospital, Lira, Uganda. ${ }^{6}$ Division of Adult Cardiology, Uganda Heart Institute, Kampala, Uganda. ${ }^{7}$ Department of Medicine, St. Francis hospital Nsambya, Kampala, Uganda. ${ }^{8}$ Departments of Physiology and Medicine, Makerere University College of Health Sciences, Kampala, Uganda. ${ }^{9}$ Department of Medicine, Mengo Hospital, Kampala, Uganda.

Received: 3 July 2017 Accepted: 14 August 2017

Published online: 24 August 2017

\section{References}

1. International-Diabetes-Federation. IDF Diabetes atlas-7th Edition. 2015. http://www.diabetesatlasorg/. Accessed 30 Nov 2016.

2. WHO. WHO-Cardiovascular diseases. 2016.http://www.who.int/mediacentre/ factsheets/fs317/en/. Accessed 6 June 2016.

3. Dalal S, Beunza J, Volmink J, Adebamowo C, Bajunirwe F, Njelekela M, et al. Noncommunicable diseases in sub-Saharan Africa: what we know now. Int J Epidemiol. 2011;40:885-901.

4. Sobngwi E, Ndour-Mbaye M, Boateng K, Ramaiya K, Njenga E, Diop S, et al. Type 2 diabetes control and complications in specialised diabetes care centres of six sub-Saharan African countries: the Diabcare Africa study. Diabetes Res Clin Pract. 2012;95:30-6.

5. Mendis S, Fukino K, Cameron A, Laing R, Filipe-Jr A, Khatib O, et al. The availability and affordability of selected essential medicines for chronic diseases in six low- and middle-income countries. Bull World Health Organ. 2007:85:279-88.

6. Jingi A, Noubiap J, Onana A, Nansseu J, Wang B, Kingue S, et al. Access to diagnostic tests and essential medicines for cardiovascular diseases and diabetes care: cost, availability and affordability in the West Region of Cameroon. PLoS One. 2014;9(11):e111812.

7. van Mourik M, Cameron A, Ewen M, Laing R. Availability, price and affordability of cardiovascular medicines: a comparison across 36 countries using WHO/HAl data. BMC Cardiovasc Disord. 2010;10:25.

8. Cameron A, Ewen M, Ross-Degnan D, Ball D, Laing R. Medicine prices, availability, and aff ordability in 36 developing and middle-income countries: a secondary analysis. Lancet. 2009;373:240-9.

9. Dabare $\mathrm{P}$, Wanigatunge $\mathrm{C}$, Beneragama $\mathrm{H}$. A national survey on availability, price and affordability of selected essential medicines for non communicable diseases in Sri Lanka. BMC Public Health. 2014;14:817.

10. Mendis S, Al-Bashir I, Dissanayake L, Varghese C, Fadhil I, Marhe E, et al. Gaps in capacity in primary care in low-resource settings for implementation of essential non communicable disease interventions. Int J Hypertens. 2012;10:1155.

11. Kibirige D, Atuhe D, Sebunya R, Mwebaze R. Suboptimal glycaemic and blood pressure control and screening for diabetic complications in adult ambulatory diabetic patients in Uganda: a retrospective study from a developing country. J Diabetes Metab Disord. 2014;13:40.

12. WHO. Prevention of cardiovascular disease pocket guidelines for assessment and management of cardiovascular risk. 2007. http://www.who.int/ cardiovascular diseases/guidelines/PocketGL.ENGLISH.AFR-D-E.rev1.pdf.

13. WHO/UGANDA. Country statistics. http://www.who.int/countries/uga/en/. (Accessed on 17 Apr 2014). 2015.

14. Bahendeka S, Wesonga R, Mutungi G, Muwonge J, Neema S, Guwatudde D. Prevalence and correlates of diabetes mellitus in Uganda: a populationbased national survey. Trop Med Int Health. 2016;21(3):405-16.

15. Guwatudde D, Mutungi G, Wesonga R, Kajjura R, Kasule H, Muwonge J, et al. The epidemiology of hypertension in Uganda: findings from the National non-communicable diseases risk factor survey. PLoS One. 2015;10(9): e0138991.

16. Zhang W, Mondo C, Okello E, Musoke C, Kakande B, Nyakoojo W, et al. Presenting features of newly diagnosed rheumatic heart disease patients in Mulago Hospital: a pilot study. Cardiovasc J Afr. 2013;24(2):28-33. 
17. Lugero C, Kibirige D, Kayima J, Mondo C, Freers J. Atrial fibrillation among the black population in a Ugandan tertiary hospital. Int J Gen Med. 2016;9:191-8.

18. Kuule J, Seremba E, Freers J. Anaemia among patients with congestive cardiac failure in Uganda - its impact on treatment outcomes. SAMJ. 2009;99(12):876-80

19. Katende D, Mutungi G, Baisley K, Biraro S, Ikoona E, Peck R, et al. Readiness of Ugandan health services for the management of outpatients with chronic diseases. Trop Med Int Health. 2015;20(10):1385-95.

20. Medicine price monitor for Uganda. No. 13. 2015. http://apps.who.int/ medicinedocs/documents/s22317en/s22317en.pdf. Accessed 16 Mar 2017.

21. WHO. World Health Organization, Health Action International. Measuring medicine prices, availability, affordability and price components 2nd edition. 2008. Available: http://www.who.int/medicines/areas/access/OMS_ Medicine prices.pdf. Accessed 26 Dec 2014

22. MOH-Uganda. Ministry of Health Republic of Uganda hospital categories http://www.health.go.ug/hospitals. (accessed on 11 Jan 2017). 2017.

23. NDA. National Drug Authority (Uganda). Drug Inspectorate Services Department http://nda.or.ug/ug/smenu/6/Drug-Inspectorate-ServicesDepartmenthtml. (accessed on 11 Jan 2017). 2017.

24. WHO. AFRO Essential medicines price indicator: WHO model list, 2007 edition. 2007.

25. UCG. http://library.health.go.ug/publications/leadership-and-governancegovernance/guidelines/uganda-clinical-guidelines-2012. Accessed on 05 Sept 2015. 2012

26. Kirchhof P, Benussi S, Kotecha D, Ahlsson A, Atar D, Casadei B, et al. 2016 ESC Guidelines for the management of atrial fibrillation developed in collaboration withEACTS. Eur Heart J. 2016:37:2893-962.

27. Steg G, James S, Atar D, Badano L, Blomstrom-Lundqvist C, Borger M, et al. ESC Guidelines for the management of acute myocardial infarction in patients presenting with ST-segment elevation. Eur Heart J. 2012;33:2569-619.

28. Roffi M, Patrono C, Collet J, Mueller C, Valgimigli M, Andreotti F, et al. 2015 ESC Guidelines for the management of acute coronary syndromes in patients presenting without persistent ST-segment elevation. Eur Heart J. 2016;37:267-315.

29. Ponikowski P, Voors A, Anker S, Bueno H, Cleland J, Coats A, et al. 2016 ESC Guidelines for the diagnosis and treatment of acute and chronic heart failure. Eur Heart J. 2016;37:2129-200.

30. WHO. Management Sciences for Health. International Drug Price Indicator Guide. 2012. Available: https://www.msh.org/resources/international-drugprice-indicator-quide. Accessed 27 Dec 2014

31. Ministry of Public Service, Republic of Uganda salary structure FY 2015-16 Primary school teachers. 2012. https://www.publicservice.go.ug/ publications/salary-scales/. Accessed 11 Jan 2017.

\section{Submit your next manuscript to BioMed Central and we will help you at every step:}

- We accept pre-submission inquiries

- Our selector tool helps you to find the most relevant journal

- We provide round the clock customer support

- Convenient online submission

- Thorough peer review

- Inclusion in PubMed and all major indexing services

- Maximum visibility for your research

Submit your manuscript at www.biomedcentral.com/submit

C) Biomed Central 